\title{
Defective Interfering Passages of Sindbis Virus: Nature of the Defective Virion RNA
}

\author{
S. I. T. KENNEDY, CELIA J. BRUTON, BARBARA WEISS, AND SONDRA SCHLESINGER* \\ Department of Biological Sciences, University of Warwick, Coventry, CV47AL, England, and Department of \\ Microbiology and Immunology, Washington University School of Medicine, St. Louis, Missouri 63110*
}

Received for publication 6 May 1975

\begin{abstract}
Defective interfering particles of Sindbis virus contain 20S RNA identical to that found in BHK cells co-infected with standard and defective virions. We have characterized these RNAs by their oligonucleotide fingerprints. Most of the oligonucleotides were identical to those found in the mRNA (26S RNA) that codes for the virion structural proteins. Three oligonucleotides found in $20 S$ RNA were absent from the $26 S$ RNA pattern and may represent sequences from the 5 ' end of the virion RNA. Previous difficulties in describing the nature of the defective virion RNA were due to the aggregated state of the RNA. Nucleocapsids obtained from standard and defective virions were essentially the same size and had about the same density, suggesting that defective particles contain more than a single molecule of $20 S$ RNA.
\end{abstract}

The accumulation of defective interfering (DI) particles in the two alpha viruses, Sindbis virus and Semliki forest virus, is now a welldocumented phenomenon $(2 \mathrm{a}, 8,10,18,19)$. DI particles generated from these virions are similar to those described for other viruses in their ability to interfere with the replication of the homologous standard virus. A definition of DI particles usually includes as one of the characteristics that the nucleic acid is deleted in viral genetic information, but until recently the nature of the deletion in the RNA of alpha virus DI particles has been obscure. The RNA or standard virions has a molecular weight of about $4 \times 10^{6}$ and a sedimentation coefficient of $42 S$. DI particles described by Shenk and Stollar appeared to contain RNA identical to the $42 S$ RNA present in standard virions (19). When Weiss and Schlesinger examined the RNA from viral preparations containing DI particles, they found that the RNA was heterogeneous (22). There seemed to be a good correlation between the degree of defectiveness of the preparation and the extent of heterogeneity, but the reason for the heterogeneity was not understood. In the past year, Bruton and Kennedy described the properties of DI particles of Semliki forest virus. In contrast to the results obtained with DI particles of Sindbis virus, the RNA isolated from the Semliki forest virus DI particles was considerably smaller than standard virion RNA (2a, 2b). The defective RNA had a sedimentation coefficient of $20 S$ and was resolved by gel electrophoresis into two distinct species with molecular weights of $0.81 \times 10^{6}$ and $0.75 \times 10^{6}$. Hybridization studies and oligonucleotide fingerprinting indicated that these two RNAs were very closely related. Thus, RNA obtained from DI particles of Semliki forest virus appears to have a large deletion covering about four-fifths of the genome.

Studies on the replication of alpha viruses have shown that infected cells synthesize two major species of viral-specific RNA $-42 S$ virion RNA and $26 S$ RNA. The latter RNA represents a subgenomic species that has a molecular weight of $1.8 \times 10^{6}$ and contains one-third of the sequences of $42 S$ RNA (21). It serves as the mRNA for the virion structural proteins $(4,5)$. When cells are co-infected with standard virions and DI particles, the pattern of viral-specific RNA is drastically altered. A new species of RNA (20S RNA) appears and the synthesis of the standard viral RNAs, in particular 265 RNA, is decreased $(2 b, 8,22)$. Weiss et al. have shown that the 20S RNA obtained from cells infected with defective passages of Sindbis virus has about $50 \%$ sequence homology with 26S RNA, based on competitive hybridization data (23). It does not, however, perform the mRNA function of $26 S$ RNA; it is not found on polyribosomes and does not stimulate protein synthesis in vitro (23).

Bruton and Kennedy found that the 20S RNA isolated from DI particles of Semliki forest virus and also obtained from BHK cells infected with both standard and defective Semliki forest virus is distinct from the comparable Sindbis 20S RNA, since it shows no sequence 
homology with the appropriate $26 S$ mRNA by hybridization (2a). Because of the reported differences in the defective RNAs isolated from BHK cells infected with Sindbis or Semliki forest virus and the previous difficulties in identifying the nature of defective Sindbis virion RNA, we decided to reexamine DI particles of Sindbis virus. Our studies confirm the sequence homology between $20 S$ and $26 S$ RNA previously based on hybridization studies. Most importantly, they clarify the nature of the defective Sindbis virion RNA. They show that DI particles of Sindbis virus contain $20 \mathrm{~S}$ RNA-identical to that found in infected cells.

\section{MATERIALS AND METHODS}

Cell cultivation and virus growth. Sindbis virus was grown on monolayers of BHK cells in plastic petri dishes or in 2.5-liter glass roller bottles and passaged according to published procedures (18). The defective late-passage virus preparations used in these studies were tested for interference as described previously (22). Passages 11 through 14 were used in the experiments described in this paper. We have not observed any qualitative differences between the different defective passages of Sindbis virus that were derived from the same initial isolate.

Labeling and purification procedures. For the isolation of $\left[{ }^{3} \mathrm{H}\right]$ uridine-labeled Sindbis virus, cells were infected at a multiplicity of 10 or more in the presence of $1 \mu \mathrm{g}$ of actinomycin D per ml. Two hours after infection, $1 \mathrm{mCi}$ of $\left[{ }^{3} \mathrm{H}\right]$ uridine in $50 \mathrm{ml}$ of medium was added to 2.5 -liter roller bottles containing about $3 \times 10^{*}$ BHK cells. Virus was harvested after 8 or $17 \mathrm{~h}$, centrifuged for $10 \mathrm{~min}$ at $2,000 \mathrm{rpm}$ to remove cellular debris, and pelleted using an International A170 rotor at $1.7 \times 10^{5} \times g$ for $2 \mathrm{~h}$. The pelleted virus was resuspended and centrifuged overnight through a composite velocity and equilibrium gradient as described by Scheele and Pfefferkorn (17). Sucrose solutions were prepared in $0.05 \mathrm{M}$ Tris-hydrochloride, $\mathrm{pH} 7.4$, containing either $0.1 \mathrm{M}$ $\mathrm{LiCl}$ and $0.0015 \mathrm{M} \mathrm{MgCl}_{2}$ (TLM) or $0.1 \mathrm{M} \mathrm{NaCl}$ and $0.001 \mathrm{M}$ EDTA. Virion RNA was extracted using $1 \%$ 2-mercaptoethanol, $2 \%$ SDS, and phenol-chloroformisoamyl alcohol (1:1:0.12). After three extractions, the aqueous phase was extracted twice with chloroform-isoamyl alcohol and then with ether.

For the isolation of $\left[{ }^{3} \mathrm{H}\right]$ uridine-labeled intracellular viral RNA, cells were washed twice with TLM buffer and scraped off the roller bottle surface with this buffer saturated with diethylpyrocarbonate. Triton X-100 was added to $1 \%$, and nuclei and cell debris were removed by low-speed centrifugation. To the remaining extract, lithium dodecyl sulfate (LDS) was added to $1 \%$, and the RNA was extracted with phenol-chloroform-isoamyl alcohol as described previously (23).

To obtain ${ }^{32} \mathrm{P}$-labeled DI $20 S$ RNA for hybridization, cells were grown in one-tenth phosphate-containing medium for $2 \mathrm{~h}$ before infection. At $2 \mathrm{~h}$ postinfection, $4 \mathrm{mCi}$ of ${ }^{32} \mathrm{P}_{\mathrm{i}}$ was added, and cells were collected and lysed $5 \mathrm{~h}$ thereafter. The RNA was purified as described above. The DI $20 S$ RNA was obtained from polyacrylamide gels by elution with 1 mM EDTA.

To obtain virion RNA for oligonucleotide fingerprinting, roller bottle cultures of BHK cells were incubated for $16 \mathrm{~h}$ before infection in phosphate-free minimal essential medium (MEM-P) containing $10 \%$ dialyzed calf serum. At $1.5 \mathrm{~h}$ postinfection, with 0.2 PFU of either standard virus or passage 13 virus per cell, $5 \mathrm{mCi}$ of ${ }^{32} \mathrm{P}_{1}$ was added to each culture in 10 $\mathrm{ml}$ of $0.02 \mathrm{M}$ HEPES ( $N$-2-hydroxyethylpiperazine$N^{\prime}$-2-ethanesulfonic acid)-buffered phosphate-free minimal essential medium containing $2 \%$ dialyzed calf serum and $0.1 \mu \mathrm{g}$ of actinomycin $\mathrm{D}$ per $\mathrm{ml}$. Extracellular virus, harvested $22 \mathrm{~h}$ postinfection, was purified as described before (11). Virion RNA was extracted using the phenol-SDS-2-mercaptoethanol procedure (13) and stored under alcohol at $-20^{\circ} \mathrm{C}$.

The techniques described for the preparation of Semliki forest virus-specified intracellular DI RNAs were used to isolate ${ }^{32} \mathrm{P}$-labeled Sindbis virus-specified 20S RNA for fingerprinting (2a).

Preparation of double-stranded 12S RNA. Total cellular RNA purified by phenol extraction was fractionated by incubation in $2 \mathrm{M} \mathrm{LiCl}$ at $4^{\circ} \mathrm{C}$ overnight. The precipitate thus formed was removed by centrifugation at $10,000 \mathrm{rpm}$ for $40 \mathrm{~min}$. The soluble fraction containing the replicative forms was precipitated with $70 \%$ alcohol and centrifuged through a 5 to $20 \%$ sucrose gradient containing $0.5 \%$ LDS for 22 $\mathrm{h}$ in the Beckman SW27 rotor at $81,800 \times g$. Either ${ }^{14} \mathrm{C}$-labeled ribosomal RNA or unlabeled reovirus RNA (kindly provided by A. Shatkin) was used as a reference marker.

Hybridization. The RNA was suspended in $250 \mu \mathrm{l}$ of $1 \mathrm{mM}$ EDTA and heated in sealed vials to $110^{\circ} \mathrm{C}$ for 2 to $3 \mathrm{~min}$ in an ethylene glycol bath. Diethylpyrocarbonate $(5 \mu \mathrm{l})$ and $8 \times \mathrm{SSC}(\mathrm{SSC}=0.15 \mathrm{M} \mathrm{NaCl}$ plus $0.015 \mathrm{M}$ sodium citrate) were added to give a $2 \times$ SSC solution. Reannealing was carried out at $66^{\circ} \mathrm{C}$ for $24 \mathrm{~h}$. The degree of RNase resistance was determined by digestion with $\mathrm{T}_{1}$ nuclease $(23 \mathrm{U} / \mathrm{ml})$ and RNase A $(20 \mu \mathrm{g} / \mathrm{ml})$ for $30 \mathrm{~min}$ at $37^{\circ} \mathrm{C}$ in $2 \times$ SSC.

Polyacrylamide gel electrophoresis. Slab gel electrophoresis of the 2aS RNA isolated from BHK cells infected with DI passages of Semliki forest virus or Sindbis virus was performed as described before (2a).

Formaldehyde denaturation. Denaturation using formaldehyde was performed according to the procedure of Simmons and Strauss (21).

Oligonucleotide fingerprinting. Each RNA species for oligonucleotide fingerprinting $\left(3 \times 10^{6}\right.$ to 10 $\times 10^{6} \mathrm{cpm}$ in 5 to $20 \mu \mathrm{g}$ of RNA) together with $100 \mu \mathrm{g}$ of carrier tRNA were recovered from alcohol by centrifugation, dissolved in $12 \mu \mathrm{l}$ of $0.01 \mathrm{M}$ Tris $(\mathrm{pH}$ 7.6) containing $10 \mu \mathrm{g}$ of RNase $\mathrm{T}_{1}$, and digested for 30 min at $37^{\circ} \mathrm{C}$. Fractionation of the $T_{1}$ oligonucleotides was by a modification of the two-dimensional polyacrylamide gel electrophoresis technique of DeWachter and Fiers (7) using the conditions of Kennedy (J. Mol. Biol., in press). Autoradiography on Kodirex X-ray film was for 3 to 5 days. 


\section{RESULTS}

Oligonucleotide fingerprints of Sindbis viral RNA. Previous studies based on competitive hybridization data indicated that the $20 S$ RNA found in BHK cells infected with defective passages of Sindbis virus contained approximately $50 \%$ of the sequences of $26 \mathrm{~S}$ RNA. This result was consistent with the difference in the molecular weights of the two species. We have now examined the relationship of these two RNA species to each other and to $42 S$ viral RNA by comparing their oligonucleotide fingerprints obtained after RNase $T_{1}$ digestion. Figure 1 shows the actual fingerprints obtained from the RNase digest of these RNAs. Figure 2 shows a tracing of the $42 S$ genomic RNA oligonucleotides of Fig. 1a. The filled spots correspond to the oligonucleotides of the structural genes (i.e., present in 26S RNA). The arrows indicate those spots that are found in the fingerprint of $20 S$ RNA shown in Fig. 1c. Nine of the twelve oligonucleotides of 2OS RNA are also seen in the 26S RNA pattern. The remaining three oligonucleotides are not characteristic of 26S RNA and are therefore from the nonstructural region of the $42 S$ RNA genome. These data not only confirm the previous hybridization data, but they also provide the additional information that viral specific sequences are found in the defective 20S RNA which are not found in 26S RNA.

Analysis of defective virion RNA. Weiss and Schlesinger had been unable to identify a unique species of RNA associated with DI particles. The pattern of RNA obtained by polyacrylamide gel electrophoresis (22) and by velocity sedimentation in sucrose gradients (Fig. 3b) showed several species of RNA. In some experiments this RNA appeared to be relatively homogeneous, sedimenting with an $S$ value slightly lower (approximately $36 S$ ) than that of the standard $42 S$ virion RNA (Fig. 4). The pattern of RNA shown in Fig. 4 was obtained by disrupting virus with $1 \%$ LDS and immediately applying the extract onto a sucrose gradient.

As a different approach to investigating the structure of the defective virion RNA, we examined its genetic complexity by $T_{1}$ nuclease digestion. To our surprise, we found the oligonucleotide pattern to be identical to the one obtained for the intracellular 20S RNA (Fig. 5).
This result suggested that the RNA must either represent a repeating polymer or an aggregate of $20 \mathrm{~S}$ RNA. To distinguish between these alternatives, we analyzed the RNA under denaturing conditions. Portions of the same standard and defective RNA preparations shown in Fig. $3 a$ and $b$ were denatured in formaldehyde and centrifuged in formaldehyde-sucrose gradients (Fig. 3c and d). The defective-passage virion RNA behaved as a single species sedimenting at essentially the same rate as the $18 S$ ribosomal RNA marker. Thus it is apparent that the RNA of Sindbis virus DI particles is identical in size and complexity to the defective 20S RNA synthesized in BHK cells infected with standard and defective virions. The reason for the extensive aggregation we have observed is not clear. Although we have not systematically investigated the cause, aggregation appears to be most extensive in $0.1 \mathrm{M} \mathrm{LiCl}$ and $0.0015 \mathrm{M} \mathrm{MgCl}_{2}$ (as shown in Fig. 4b). Aggregation of the DI virion 20S RNA may be a nonspecific, salt-mediated phenomenon resulting from the particular primary and secondary structure of this deleted RNA or it may in fact represent some type of special interaction required for and related to the packaging of this small RNA molecule into virus particles. A specific aggregation among homologous RNA species has recently been proposed for the $18 S$ viral transcripts of Sendai virus by Roux and Kolakofsky (16).

Structure of nucleocapsids of DI particles. Although DI particles of Sindbis virus have not been reproducibly separated from standard virions (20; our unpublished data), it seemed feasible to try to separate standard and defective nucleocapsids, since the RNA-to-protein ratio for nucleocapsids $(0.38)$ is much greater than that for intact virions $(0.06)$ (12). We would expect that a defective nucleocapsid containing an RNA molecule of $0.9 \times 10^{6}$ would be distinguishable from one containing the virion RNA with a molecular weight of about $4 \times 10^{6}$. However, nucleocapsids derived from highly defective preparations of virus with an RNA profile identical to that shown in Fig. 3d sedimented to equilibrium in $\mathrm{CsCl}$ at a density only slightly less $\left(\rho=1.4803 \mathrm{~g} / \mathrm{cm}^{3}\right)$ than similarly treated standard viral nucleocapsids $\left(\rho=1.4906 \mathrm{~g} / \mathrm{cm}^{3}\right)$ (Fig. 6a). Furthermore, these defective nucleocapsids were indistinguishable from standard

FIG. 1. Oligonucleotide fingerprints of Sindbis viral RNAs. The 42S (a) and 26S RNAs (b) were isolated from BHK cells infected with standard Sindbis virus. The 20S RNA (c) was isolated from cells infected with a passage of Sindbis virus containing DI particles. The isolation of RNA and the $T_{1}$ RNase digestion and electrophoretic separation of the oligonucleotides are described in Materials and Methods. The first dimension is from left to right, the second from top to bottom. In this and subsequent fingerprints, only the larger, characteristic oligonucleotides (Kennedy, in press) are shown. 


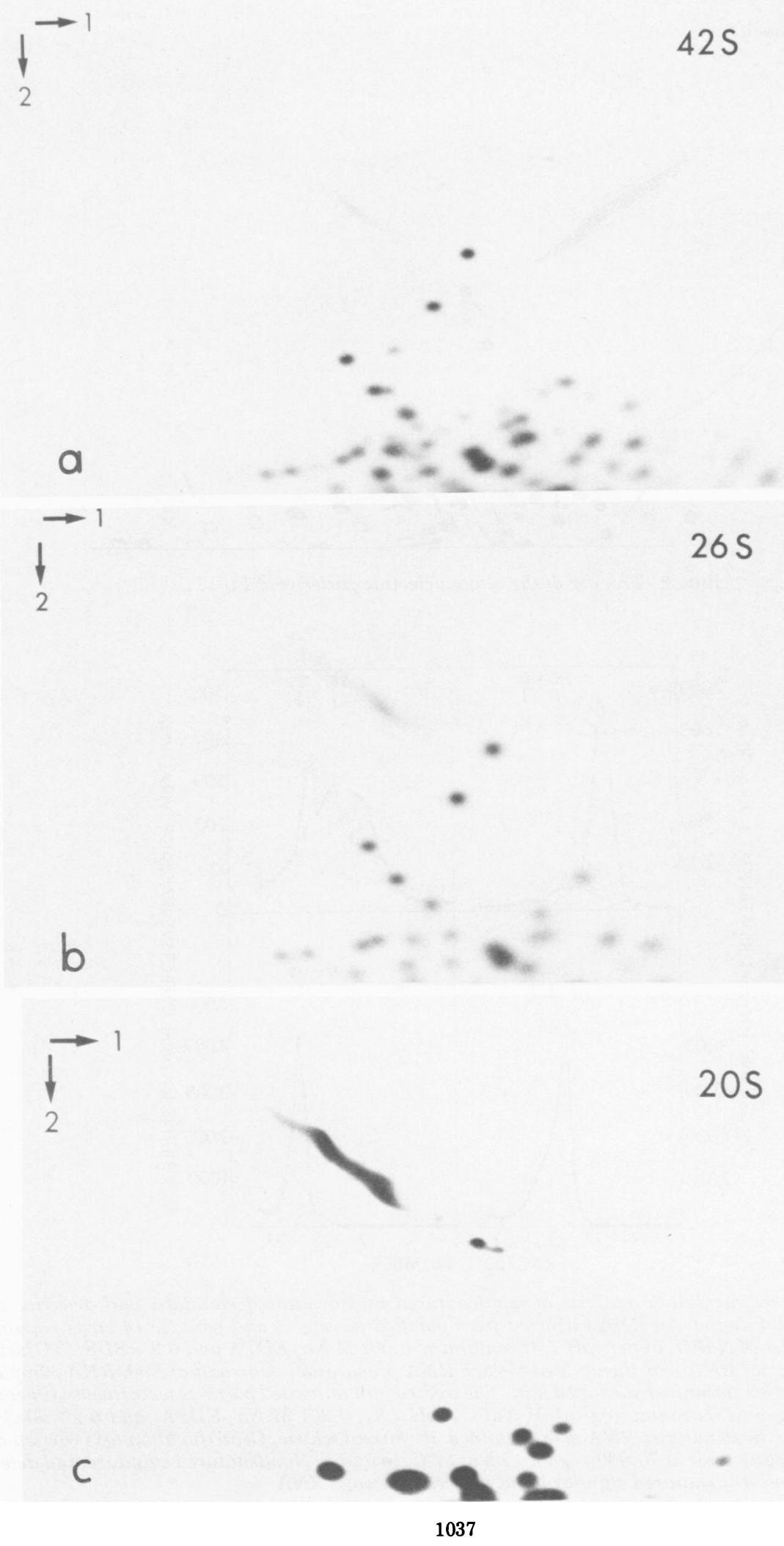



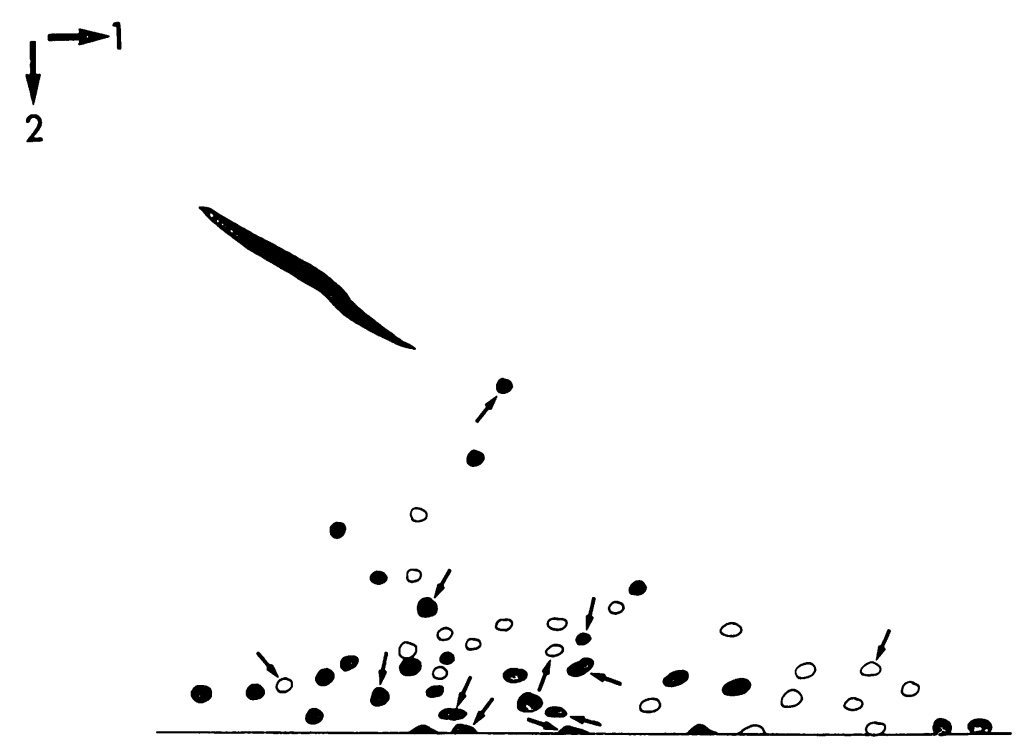

Fig. 2. Tracing of the oligonucleotide patterns of Fig. 1.

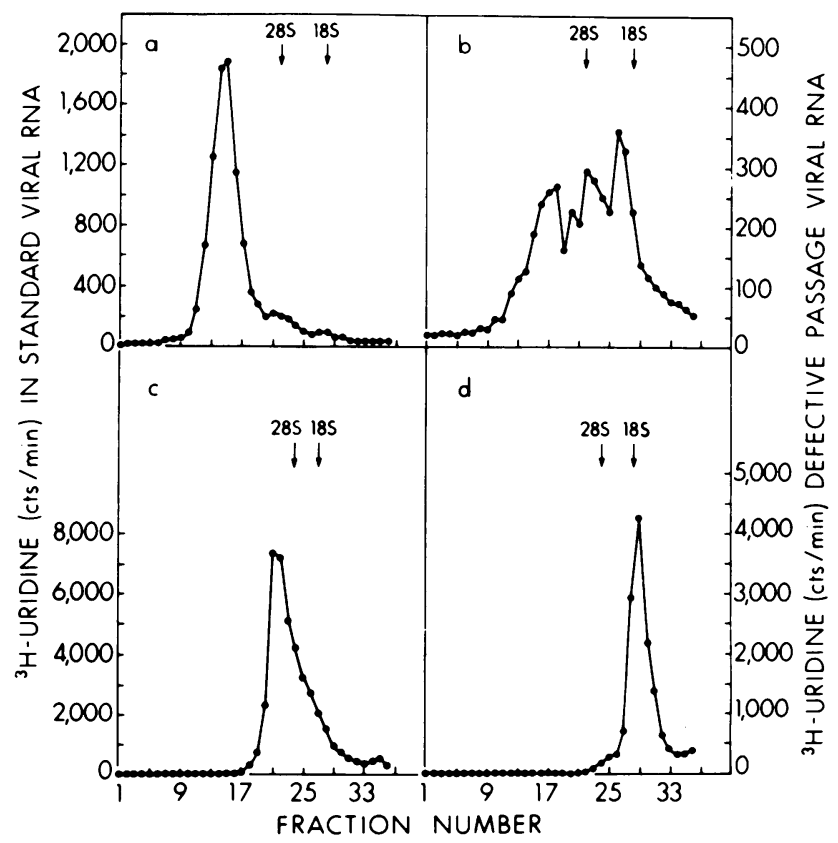

FIG. 3. Velocity sedimentation analysis of nondenatured and denatured standard and defective virion RNA. $\left[{ }^{3}\right.$ H Juridine-labeled virion RNA extracted from purified passage 3 and passage 14 virus populations was suspended in $0.1 \mathrm{M} \mathrm{NaPO}_{4}$ buffer ( $\mathrm{pH}$ 7.4) containing $0.001 \mathrm{M} \mathrm{Na}{ }_{2} E D T A$ and $0.2 \% \mathrm{SDS}$. $\left.{ }^{14} \mathrm{C}\right]$ uridinelabeled BHK ribosomal RNA was then added to each RNA preparation. One-half of each RNA sample was incubated at $63^{\circ} \mathrm{C}$ in $3 \%$ formaldehyde for $10 \mathrm{~min}$. The treated and untreated portions were then sedimented in 15 to $30 \%$ sucrose gradients containing $0.1 \mathrm{M} \mathrm{NaPO}+\left(\mathrm{pH} \mathrm{7.4)}, 0.001 \mathrm{M} \mathrm{Na} \mathrm{i}_{2}\right.$ EDTA, and $0.2 \% \mathrm{SDS}$. The gradients used with the denatured RNA also contained $3 \%$ formaldehyde. Centrifugation was carried out in the International $S B 283$ rotor at $70,000 \times g$ for $17 \mathrm{~h}$ at $17^{\circ} \mathrm{C}$. (a and b) Nondenatured standard and defectivepassage RNA; (c and d) denatured standard and defective-passage RNA. 


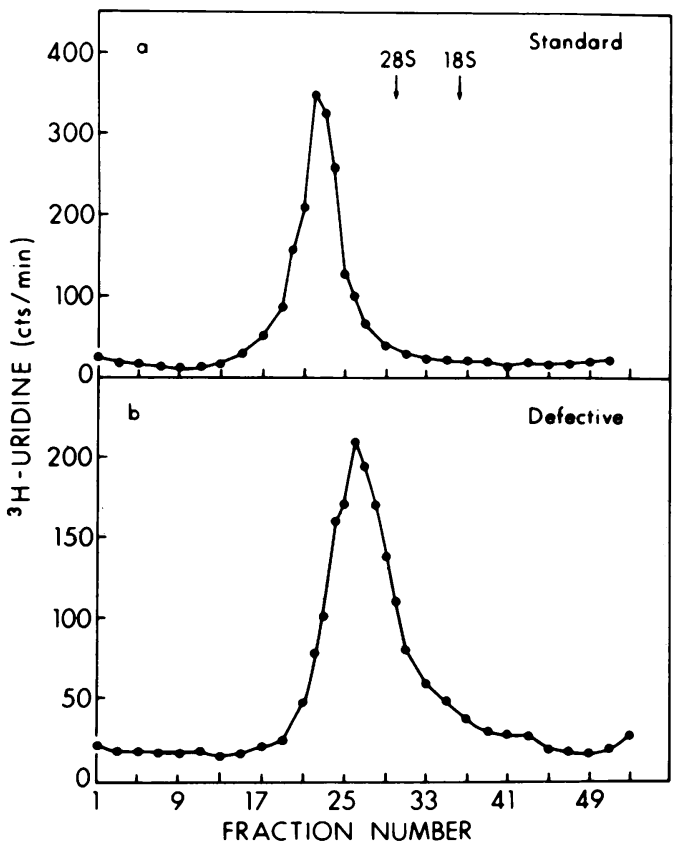

FIG. 4. Velocity sedimentation analysis of LDSlysed standard and defective virions. Purified standard (a) and defective (b) virions suspended in TLM buffer (see Materials and Methods) were treated with $1 \%$ LDS and sedimented in 15 to $30 \%$ sucrose gradients in TLM buffer containing $0.5 \%$ LDS for $17 \mathrm{~h}$ at $62,000 \times g$ in a Beckman $S W 27$ rotor at $15^{\circ} \mathrm{C}$.

nucleocapsids by rate zonal sedimentation in a sucrose gradient (Fig. 6b). Thus, it appears that defective and standard nucleocapsids are essentially the same size and do not differ significantly in their protein-to-RNA mass ratio. These findings and the observation that DI particles of Semliki forest virus and nucleocapsids derived from them are more dense than their standard viral counterparts (2a) suggest that each DI particle encapsidates more than one 20S RNA molecule.

Comparison of 20S RNA from Sindbis and Semliki forest viruses. Although the DI RNAs of Sindbis virus and Semliki forest virus have similar sedimentation constants (20S), they migrate differently during polyacrylamide gel electrophoresis (Fig. 7). The 20S RNA associated with Semliki forest virus has been separated into two species that have extremely similar nucleotide sequences, as judged by oligonucleotide fingerprinting and by hybridization studies (2a). The 20S RNA obtained from BHK cells infected with defective passages of Sindbis virus also shows some evidence for a second component, but in this case the lower-molecular-weight species represents only a minor frac- tion $(<15 \%)$ of the RNA and is not detected reproducibly.

RFs found in cells infected with standard and defective Sindbis virus. A double-stranded or replicative form (RF) of the $42 S$ virion RNA can be isolated from cells infected with standard Sindbis or Semliki forest virus $(2,21)$. This RF has a sedimentation constant of $23 S$ and a calculated molecular weight of $8.8 \times 10^{6}$. The major species of RF synthesized in BHK cells infected with DI passages of these viruses has a sedimentation constant of about $12 S(2,19$; Fig. 8). Our value of $12 S$ for the defective Sindbis RF was obtained using reovirus double-stranded RNA as markers. To determine the relationship between this $12 S \mathrm{RF}$ and the $20 \mathrm{~S}$ singlestranded defective RNA, we carried out hybridization studies using ${ }^{3:} \mathrm{P}$-labeled $20 \mathrm{~S}$ RNA and $\left[{ }^{3} \mathrm{H}\right]$ uridine-labeled $12 S$ double-stranded RNA (Table 1). The $12 S \mathrm{RF}$ was present in excess so that its reassociation was not affected by the addition of the ${ }^{32} \mathrm{P}$-labeled $20 \mathrm{~S}$ RNA (21). The data given in Table 1 show that the $12 S$ RF contains at least $70 \%$ of the sequences present in the defective 20S RNA. However, since the efficiency of reannealing of the $12 S \mathrm{RF}$ alone is about $80 \%$, it is most probable that this RF is a true duplex of the 20S DI RNA.

Cells infected with Semliki forest virus produce two species of defective RFs which can be separated by sucrose gradient centrifugation and by polyacrylamide gel electrophoresis but which are indistinguishable in hybridization analyses (2b). We have not found any indication that the $12 S \mathrm{RF}$ isolated from Sindbis virus-infected cells consists of two components.

\section{DISCUSSION}

A more complete picture of DI particles of alpha viruses is emerging based on the studies presented in this paper and on our earlier work with Sindbis and Semliki forest virus $(2 a, 2 b$, 22, 23). The particular DI particles of Sindbis virus that we have characterized contain RNA representing about one-fifth the size of the virion genome. Most of the sequences are identical to those found in the structural genes of the virion RNA. These sequences are located at the $3^{\prime}$ end of the molecule (Kennedy, in press). The fingerprint of the nuclease digest of Sindbis $20 S$ RNA indicates, however, that part of the nucleotide sequence of this molecule is not found in $26 S$ RNA. Although we do not know the precise sequence location of this part of the 20S RNA, we suggest that it might represent the 5 ' terminal region of the genome. This idea has a precedent in Semliki forest virus DI RNAs, in which the 20S RNA species have 


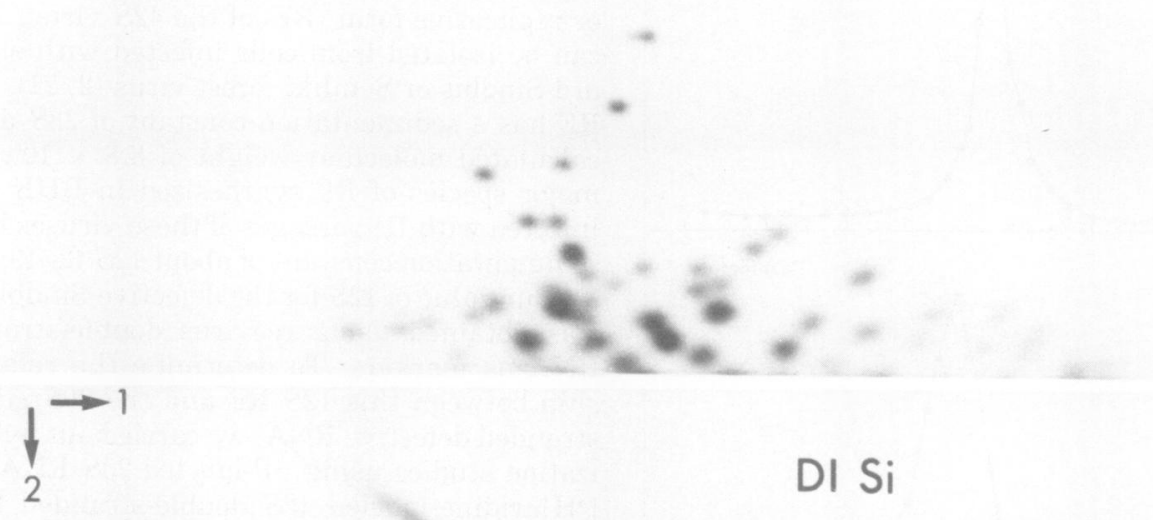

FIG. 5

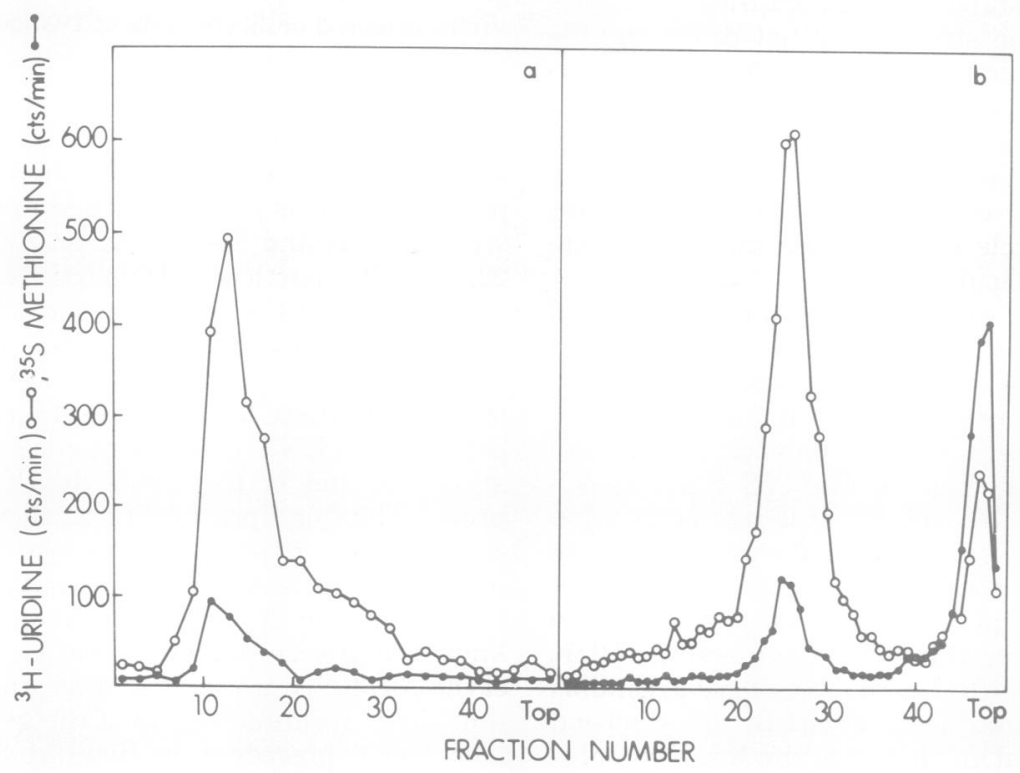

Fig. 6 


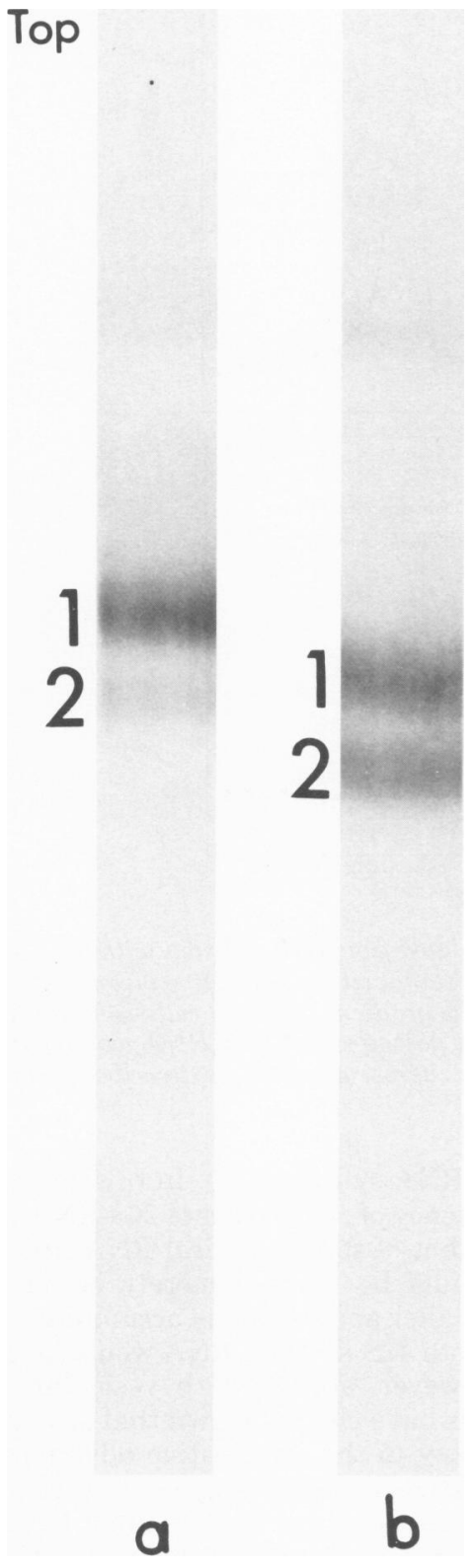

Fig. 7. A comparison of the polyacrylamide gel recently been shown to contain the nucleotide sequences present at both the $5^{\prime}$ and $3^{\prime}$ ends of the $42 S$ virion RNA (Kennedy, in press). If Sindbis 20S RNA also contains the terminal sequences of the standard virus genome, and experiments are in progress to investigate this, then a general model for the generation of the DI RNAs of alpha viruses can be proposed in which intramolecular recombination during RNA synthesis results in a huge internal deletion and the production of a fragment(s) containing both ends of the virion RNA.

The organization of DI RNA within the alpha virus nucleocapsid is unclear. We have been unable to detect a difference in the size or density of nucleocapsids derived from standard Sindbis virus and those obtained from DI particles. Furthermore, Bruton and Kennedy (2a) found that defective nucleocapsids were more dense than those of standard Semliki forest virus. It is difficult to reconcile these findings with the fact that the molecular weight of the defective RNA is four to five times less than that of the standard virion RNA unless more than one molecule of DI RNA is encapsidated per DI particle. Perhaps there is some particular structure or quantity of RNA required to form the icosahedral nucleocapsid of these virions. Furthermore, the packaging of more than one RNA molecule per nucleocapsid may favor aggregation and explain why the defective RNA shows such a strong tendency to aggregate.

The question of how DI particles of alpha viruses interfere with the replication of standard virus is presently under investigation. When cells are co-infected with standard and defective alpha viruses, there is extensive interference with the synthesis of both virion $42 S$ RNA and viral-specific 26S RNA. This inhibition is correlated with an enrichment in $20 S$ defective RNA. The latter RNA, from either Sindbis or Semliki forest virus, does not code

electrophoresis patterns of intracellular $20 S$ defective RNA from Sindbis virus (a) and Semliki forest virus (b).

Fig. 5. Oligonucleotide fingerprints of RNA isolated from standard virions (42S RNA) and from a passage of Sindbis virus containing DI particles.

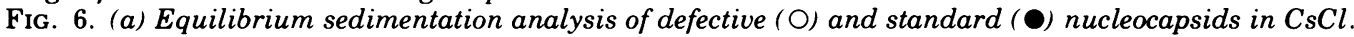
${ }^{3} \mathrm{H} /$ uridine-labeled defective-passage virions and $\left[{ }^{35} \mathrm{~S}\right]$ methionine-labeled standard virions were disrupted with $1 \%$ Nonidet $P-40$ for $1 \mathrm{~h}$ at room temperature. The nucleocapsids were pelleted free of envelope lipid and proteins by centrifugation through a layer of $15 \%$ sucrose. The resulting pellet was resuspended in $0.1 \mathrm{M}$ phosphate buffer and fixed in $4 \%$ formaldehyde for $1 \mathrm{~h}$. Centrifugation in CsCl was carried out in the Beckman SW50.1 rotor at $234,000 \times \mathrm{g}$ for $17 \mathrm{~h}$ at $4^{\circ} \mathrm{C}$. (b) Rate-zonal sedimentation analysis of Nonidet $P$-40disrupted standard and defective-passage virions. $\left[{ }^{3} \mathrm{H}\right]$ uridine-labeled defective $(O)$ and $\left[{ }^{35} \mathrm{~S}\right]$ methioninelabeled standard (O) virions were first mixed and then disrupted with $1 \%$ Nonidet P-40. Sedimentation through a 15 to $30 \%$ sucrose gradient was carried out for $3.5 \mathrm{~h}$ in a Beckman SW27 rotor at $95,400 \times \mathrm{g}$. 


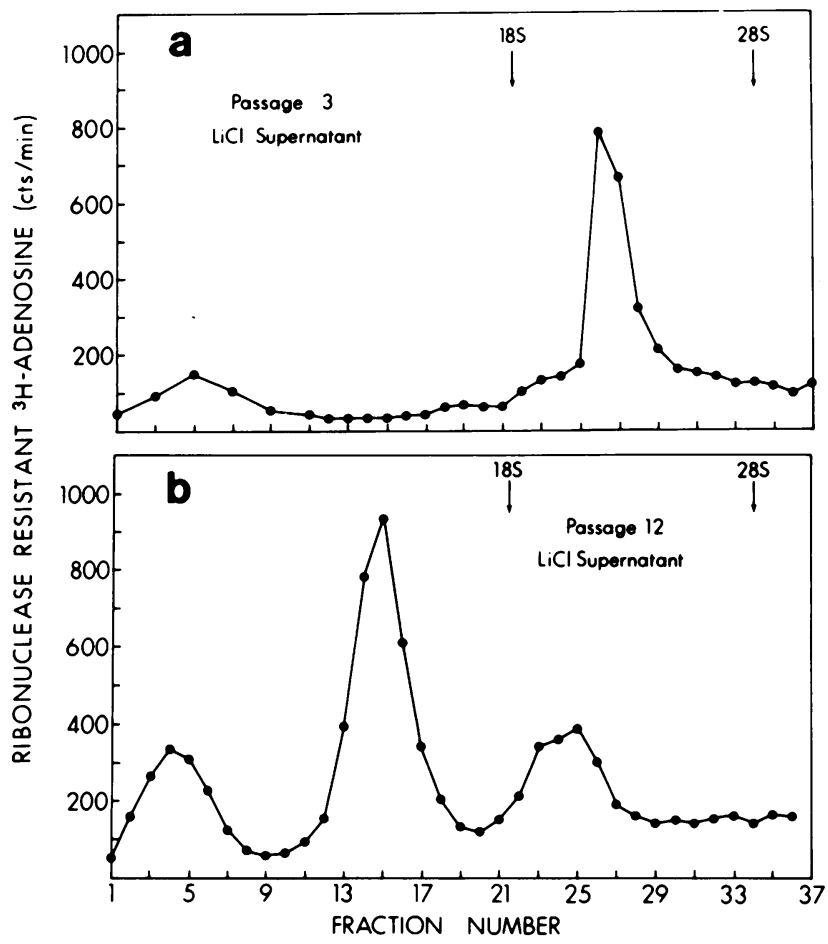

FIG. 8. Sedimentation of the double-stranded RNA species isolated from cells infected with Sindbis virus. (a) Cells infected with standard virus; (b) cells co-infected with standard and defective virions. Each point represents the RNase resistance of the RNA at that position in the gradient. Infected cells were labeled with $\left[{ }^{3} \mathrm{H}\right.$ ]adenosine $\left(30 \mathrm{Ci} / \mathrm{mmol}, 1 \mathrm{mCi} / 3 \times 10^{8} \mathrm{cells}\right)$ from 2 to $12 \mathrm{~h}$ postinfection. The $\mathrm{RNA}$ was purified and fractionated using $2 \mathrm{M} \mathrm{LiCl}$ and sedimented through a 5 to $20 \%$ sucrose gradient as described in Materials and Methods.

TABLE 1. Hybridization of single-stranded DI $20 S$ $R N A$ to $12 S R F$

\begin{tabular}{|c|c|c|c|}
\hline \multirow{2}{*}{$\begin{array}{l}20 S \\
\text { RNA }\left(^{(32} \mathrm{P}\right) \\
(\text { cpm })\end{array}$} & \multirow{2}{*}{$\begin{array}{c}12 S \\
\operatorname{RF}\left(\left[{ }^{3} \mathrm{H}\right] \text { uridine }\right) \\
(\mu \mathrm{g} / \mathrm{ml})\end{array}$} & \multicolumn{2}{|c|}{ RNase resistance } \\
\hline & & ${ }^{32} \mathrm{P}$ & ${ }^{3} \mathrm{H}$ \\
\hline 700 & & 1.9 & \\
\hline & 0.45 & & 78 \\
\hline 700 & 0.45 & 64 & 64 \\
\hline 700 & 0.91 & 71 & 80 \\
\hline 1,400 & 0.91 & 68 & 70 \\
\hline 700 & 2.3 & 71 & 64 \\
\hline
\end{tabular}

${ }^{a}$ Expressed as the percentage of total added radioactivity (in either ${ }^{32} \mathrm{P}$-labeled single-stranded $20 S$ RNA or $\left[{ }^{3} \mathrm{H}\right]$ uridine-labeled double-stranded $12 \mathrm{~S}$ RNA) that becomes resistant to both $T_{1}$ nuclease and RNase $A$ after denaturation and reannealing under the conditions described in Materials and Methods. Before denaturation, the $12 S \mathrm{RF}$ was completely resistant to such digestion. Under the hybridization conditions used, this RF never reassociated to better than $80 \%$, as shown in column 4 .

for viral-specific proteins, and the genetic information for the viral replicase must be provided by the co-infecting standard virus. The amount of viral replicase appears to be a limiting factor in viral RNA synthesis (6). In this situation, if the efficiency of replication of $20 S$ RNA is identical to that of standard viral RNA, its enrichment would be assured merely because it is much smaller and its rate of accumulation relative to both $42 S$ and $26 S$ RNA would be greater (2b). However, studies with vesicular stomatitis virus have clearly shown that size alone is not the key to the competitive advantage certain DI RNAs have and suggest that structural characteristics of the RNA related to enzyme recognition may be important in selection and enrichment $(10,15)$. The recent studies of Mills et al. (14) involving the in vitro replication and selection of $\mathrm{Q} \beta$ variant RNA molecules bear on this point. They suggest that the secondary and tertiary structure of an RNA molecule may play a decisive part in determining its selective affinity for replicase. This may be important in explaining how DI particles with unique and different primary sequences can be selected naturally.

\section{ACKNOWLEDGMENT}

This work was supported by Public Health Service grant A111377 to S.S. 


\section{LITERATURE CITED}

1. Anderson, L. E., and W. O. McClure. 1973. An improved scintillation cocktail of high solubilizing power. Anal. Biochem. 51:173-179.

2. Bruton, C. J., and S. I. T. Kennedy. 1975. Semliki Forest virus intracellular RNA: properties of the multi-stranded RNA species and kinetics of positive and negative strand synthesis. J. Gen. Virol. 28:111127.

2a. Bruton, C. J., and S. I. T. Kennedy. 1976. Defectiveinterfering particles of Semliki forest virus: structural differences between standard virus and defective-interfering particles. J. Gen. Virol. 31:383-396.

2b. Bruton, C. J., and S. I. T. Kennedy. 1976. Defectiveinterfering particles of Semliki forest virus: intracellular events during interference. J. Gen. Virol. 31:397-416.

3. Cancedda, R., and M. J. Schlesinger. 1974. Formation of Sindbis virus capsid protein in mammalian cellfree extracts programmed with viral messenger RNA. Proc. Natl. Acad. Sci. U.S.A. 71:1843-1847.

4. Cancedda, R., R. Swanson, and M. J. Schlesinger. 1974. Effects of different RNAs and components of the cell-free system on in vitro synthesis of Sindbis viral proteins. J. Virol. 14:652-663.

5. Clegg, J. C. S., and S. I. T. Kennedy. 1975. Translation of Semliki Forest intracellular 26S RNA. Characterization of the products synthesized in vitro. Eur. J. Biochem. 53:175-183.

6. Cole, C. N., and D. Baltimore. 1973. Defective interfering particles of poliovirus. IV. Mechanism of enrichment. J. Virol. 12:1414-1426.

7. De Wachter, R., and W. Fiers. 1972. Preparative twodimensional polyacrylamide gel electrophoresis of ${ }^{32}$ P-labeled RNA. Anal. Biochem. 49:184-197.

8. Eaton, B. T., and P. Faulkner. 1973. Altered pattern of viral RNA synthesis in cells infected with standard and defective Sindbis virus. Virology 51:85-93.

9. Gibson, W., and B. Roizman. 1974. Proteins specified by herpes simplex virus. $X$. Staining and radiolabeling properties of $B$ capsid and virion proteins in polyacrylamide gels. J. Virol. 13:155-165.

10. Huang, A. S. 1973. Defective interfering viruses. Annu.
Rev. Microbiol. 27:101-117.

11. Kennedy, S. I. T. 1974. The effect of enzymes on structural and biological properties of Semliki Forest virus. J. Gen. Virol. 23:129-143.

12. Laine, R., H. Söderlund, and O. Renkonen. 1973. Chemical composition of Semliki Forest virus. Intervirology 1:110-118.

13. Martin, B. A. B., and D. C. Burke. 1974. The replication of Semliki Forest virus. J. Gen. Virol. 21:19-29.

14. Mills, D. R., F. R. Kramer, C. Dobkin, T. Nishihara, and S. Spiegelman. 1975. Nucleotide sequence of $\mathrm{mi}$ cro-variant RNA: another small replicating molecule. Proc. Natl. Acad. Sci. U. S. A. 72:4252-4256.

15. Prevec, L., and C. Y. Kang. 1970. Homotypic and heterotypic interference by defective particles of vesicular stomatitis virus. Nature (London) 228:25-27.

16. Roux, L., and D. Kolakofsky. 1975. Isolation of RNA transcripts from the entire Sendai viral genome. J. Virol. 16:1426-1434.

17. Scheele, C. M., and E. R. Pfefferkorn. 1969. Kinetics of incorporation of structural proteins into Sindbis virions. J. Virol. 3:369-375.

18. Schlesinger, S., M. Schlesinger, and B. W. Burge. 1972. Defective virus particles from Sindbis virus. Virology 48:615-617.

19. Shenk, T. E., and V. Stollar. 1973. Defective-interfering particles of Sindbis virus. I. Isolation and some chemical and biological properties. Virology 53:162173.

20. Shenk, T. E., and V. Stollar. 1973. Defective interfering particles of Sindbis virus. II. Homologous interference. Virology 55:530-534.

21. Simmons, D. T., and J. H. Strauss. 1972. Replication of Sindbis virus. I. Relative size and genetic content of 26S and 49S RNA. J. Mol. Biol. 71:599-613.

22. Weiss, B., and S. Schlesinger. 1973. Defective interfering passages of Sindbis virus: chemical composition, biological activity and mode of interference. J. Virol. 12:862-871.

23. Weiss, B., D. Goran, R. Cancedda, and S. Schlesinger. 1974. Defective interfering passages of Sindbis virus: nature of the intracellular defective viral RNA. J. Virol. 14:1189-1198. 